\title{
A Study on the Cultivation of Critical Thinking Ability of English Majors
}

\author{
Zhen Zhou \\ Foreign Language School, Nanchang Normal University, Nanchang, Jiangxi, China
}

\begin{abstract}
The critical thinking ability is the premise and foundation of innovation ability. It is also an important goal of talents training in higher education. College English teaching should not only focus on the cultivation of students' English knowledge and skills, but also the cultivation of students' critical thinking ability. This article first discusses the connotation of critical thinking ability, followed by theoretical foundation introduction and analysis of the problems of critical thinking cultivation of English majors, and finally puts forward the countermeasures of cultivating students' critical thinking from the following eight aspects: paying attention to classroom questioning skills, changing the classroom teaching mode, creating relaxing teaching atmosphere, building a new student evaluation system, designing the classroom teaching reasonably and improving teachers' critical thinking ability and raising students' awareness of critical thinking ability self training, adopting PBL teaching method, in order to effectively cultivate students' independent thinking and judgment ability, and to better improve the teaching effect of college English.
\end{abstract}

Index Terms - English major, critical thinking, questioning, teaching model, evaluation

\section{INTRODUCTION}

In the present era of mass data and information explosion, the core of international society competition is talent competition. Innovative thinking ability is one of the most important criteria for measuring the quality of personnel training, and training innovative talents has become one of the main goals of higher education. The law of higher education of People's Republic of China (1999) points out that the task of higher education in China is to cultivate advanced professional talents with innovative spirit and practical ability. It is obvious that the cultivation of students' creative thinking ability is an important task in our country's education. The core of innovative talents is innovative ability, while the premise of innovative thinking is critical thinking. Therefore, the cultivation of critical thinking is very important. Cultivating critical thinking ability is also the foundation of information processing ability and autonomous learning ability.

However, contemporary Chinese college students generally lack the spirit of innovation and critical awareness. For a long time, the cultivation of students' innovative thinking ability in college teaching is hugely ignored, and it is the same with the education of critical thinking. The traditional "jug and mug" cramming method of teaching and exam oriented education bound students' thinking and innovation awareness, and a majority of students only focus on rote learning, generally lack the spirit of independent thinking. Therefore, in order to change the status quo, we must change the educational concept and way of thinking, arouse students' critical thinking awareness and train students' critical thinking, which is of great importance for the improvement of students' innovative ability.

In recent years, critical thinking has been the focus of research at home and abroad, and the development of critical thinking ability of college students has been widely concerned by many experts and scholars (Siegel, 1988; Paul, 1993; Halpern, 1999; Norris, 2001; Ricketts, 2003; Wu, 2015). The study of experts and scholars on the critical thinking ability of college students concentrated on the aspects such as, the current situation, questionnaire scale development, training methods, difference between arts and science students, and academic achievement, and its relationship between reading and writing, influence on the efficiency of language teaching mode on critical thinking ability of English majors and so on and it has achieved certain results (Gao, 1999; Han, 2009 Huang; Wen, 2010, 2011; Li; Ren, 2013; Ma, 2016). But at present, the study into the critical thinking ability taking English majors in second batch university as the subject is still scarce, therefore the article attempts to enrich the study of the critical thinking ability and supply some reference for the critical thinking ability cultivation in the college English teaching.

\section{Connotation of Critical Thinking Ability}

The word "critique" originates in Greece, which refers to questioning, analysis, evaluation and so on. Socrates is recognized as the founder of western critical thinking. In modern times, Dewey (1933) pointed out that critical thinking includes reflecting on problems, analysis of the status quo, and actively participating in the combination and extracting steps of analysis and conclusion. Critical thinking ability covers interpretation, analysis, evaluation, speculation, explanation and self adjustment ability, which shows that it does not yield authority and does not blindly confidently seek authenticity, and it possess the traits of openness, analysis and tenacity (Facione, 1992). Critical thinking is a prudent and doubtful thinking activity. It guides people's beliefs and actions through observing, reflecting, reasoning 
and communicating psychological processes (Zhong, 2002). Critical thinking is conscious thinking through certain criterion of thinking, and ultimately making rational judgment, and then improving the rational thinking, and reflective thinking is the thinking skill. It takes a logical method as the foundation, combined with the people's everyday thinking and psychology, the development tendency of a series of thinking skills and ability, which are extremely useful thinking skill, so that we can distinguish the real and useful information from the vast amounts of information data (Wen, 2009).

As for the theoretical model of critical thinking, the Socrates method is the earliest critical thinking model in Europe. The Socratic method mainly adopts dialogue, discussion, and heuristic teaching method, in which through posing questions to the students, each student's answer constantly exposes contradictions, and the teacher guides students to draw the general conclusion. The core of this approach is to emphasize thinking clearly and carefully through questioning the traditional concept of authenticity, and cultivate students' independent thinking and critical thinking ability. At present, among the domestic and foreign theoretical model of critical thinking, the most famous four models are as follows: the Delphi study model, three element model (Paul \& Elder model), Anderson et al multi level model, and cognitive ability hierarchy theory model (Wen, 2009). The Delphi research model believes that critical thinking ability includes cognitive and affective qualities. Cognitive skills include such six parts as understanding, analysis, inference, explanation, evaluation and self correction. Affect refers to seeking truth and open-mind, analytical skills, systematic, self-confidence, which explores seven personality traits and cognitive maturity. The three-element structure model divides critical thinking into eight elements and nine standards. Eight elements refers to purpose, problems, concepts, information, conclusions and assumptions, implication and perspective and nine standards means clear and truth, accuracy, relevance, depth, breadth, meaning, logic and justice. And the Anderson et al cognitive multi-layer model divides the thinking skills into a lower level and a higher level. The lower level of thinking skills includes memory and understanding, and the higher level of thinking skills includes application, analysis, evaluation and creation. This model classifies all kinds of skills in critical thinking ability, highlights the process and dynamics of thinking skills, and explains the relationship between critical thinking ability and innovative ability. Wen (2009) proposed that the theoretical model of speculative ability level includes two aspects, that is, the ability of meta-thinking and the ability of thinking. Meta-cognition is the highest level in the hierarchical theoretical model, that is, the skills of planning, managing, monitoring and evaluating your own thinking. And the ability of thinking is divided into cognitive skills and affective qualities.

\section{THEORY FOUNDATION}

Critical thinking ability is based on the famous constructivist theory. Constructivist theory (constructivism) is also translated as structuralism, which is a branch of cognitive psychology. Jean Piaget, Jerome Bruner, and George Kelly are the three recognized authorities in the field (Burden, 2000). An important concept of constructivism is schema, which refers to the way individuals understand and think about the world. It can also be regarded as a framework or organizational structure of mental activity. Schema is the starting point and core of cognitive structure or it is the basis of human cognition. Therefore, schema formation and change is the essence of cognitive development, cognitive development is influenced by three processes: assimilation, adaptation and balance.

Besides, the theory of constructivism is very rich in content, but its core can be summed up with a word: student-centered, emphasizing significance of students' active exploration and independent construction and discovery of knowledge. Constructivists think that knowledge cannot be transferred from teacher to learner by simple textbook teaching. The teachers should not tell the students what concepts they should construct and how they should construct them during learning and they should present topics, concepts and other related information in the form of problems. It is clear that all too often traditional language teaching attaches too much attention to memorizing and repeating, which cannot efficiently guide students to do deeper and further thinking. Teachers should encourage and guide learners to put forward their own questions, raise their own hypotheses and seek the right answers, which is the nature of learning. Constructivist teachers encourage students to constantly assess how the activity is helping them gain understanding. By questioning themselves and their strategies, students in the constructivist classroom ideally become "expert learners." This gives them ever-broadening tools to keep learning. With a well-planned classroom environment, the students learn how to learn. Constructivism lays theoretical supporting for critical thinking cultivation.

\section{The Problems In ENGLiSh MaJor TEACHING}

"English Teaching Syllabus for English Majors" (2000) pointed out that we should strengthen the cultivation of students' critical thinking ability and innovation ability to consciously train students' analysis and synthesis, abstraction and generalization, multi angle analysis and other thinking ability and the innovative ability and guide them to find the problems and solve the problem in the teaching of specialized courses. The teacher should have correct handling of language skills and thinking ability and innovation ability in teaching, which are indispensable. But up to now, the national English major teaching has made slow progress in cultivating students' critical thinking ability. College English teaching still adopts the traditional cramming teaching method, teacher centered, and teachers dominate the whole class and emphasize too much on language knowledge and structure. The traditional teaching way ignores students' thinking, and students are busy taking notes, passively accept the teacher's point of view, blindly accepting teacher's absolute 
authority but lack of analysis, identification, evaluation and critical awareness. Students rarely have their own ideas, and do not dare to question and they do not have the habit of thinking independently. This traditional teaching is not conducive to the cultivation of students' critical thinking ability. Therefore, the cultivation of critical thinking is very important for the students of English majors.

\section{Countermeasures of Cultivating Critical Thinking Ability}

\section{A. Paying Attention to the Skills of Asking Questions in the Classroom}

In the English classroom, that teachers design effective classroom questions is very important to improve students' critical thinking ability and innovative ability, and the most effective way is to carry out effective questioning of teachers, because teachers' effective questions can guide the students to use critical thinking way of thinking, so as to improve the ability of critical thinking. For example, in the English reading class, displaying questions generally appear in the initial stage of text reading, teachers ask questions about the words of the text, details or textual structure, and students can quickly find the answer form the text, and the understanding of the surface information will be able to answer the question. According to the students' level, teachers can design further mining problem to understand the text deeper. If students answer the questions, they need to refer to and dig text information deeper, combine their own knowledge and experience, analyze and compare information, and do reasoning and summary conclusion. Besides, assessment questions are generally used for the final stages of text processing, and teachers guide students to evaluate, summarize and practice.

\section{B. Changing the Mode of Classroom Teaching}

To enhance students' critical thinking ability, we must transform classroom teaching mode and broaden students' horizons so that they can not only acquire knowledge, but also apply knowledge to solve practical problems and innovate. The classroom teaching mode should be established under the guidance of the concept of ecological teaching. Teachers should make full use of multimedia, multi-modal teaching mode and carry out cooperative learning among students. The difference of critical thinking and traditional blind way of thinking is that it emphasizes the individual differences, therefore, teachers should be open-mined and tolerant and respect objectivity, rigor, rationality and logic and welcome students' various views and reasoning, and give them objective, reasonable and rigorous praise and encouragement, and try to avoid some set conclusions as to classroom discussion and debate topics in order to ensure the effect of classroom training of critical thinking. In the use of teaching materials, classroom teaching should take different levels of students into consideration and vary the activities and exercises. Simple tasks mainly involve both simple imitation and memory, but students also have to exchange for the purpose of language output. In class, students not only have to master and practice the basic knowledge of the text, but there should also be extension activities. Students are required to accept and use the knowledge of the language, and also required to develop their critical thinking.

\section{Creating a Relaxing Teaching Atmosphere}

The premise and foundation of the creative activities are psychological security and freedom, and only psychological security can lead to psychological freedom, and can also lead to the creativity of learning. English classroom must create a relaxing and free learning environment, so that it is more conducive to students' learning. The cultivation of college students' critical thinking ability also needs to create a relaxing and free learning environment actively, so that students can actively handle the relationship between thinking and learning, so that students can think and learn happily and creatively. Critical thinking puts emphasis on high level of thinking ability and sensitivity of students, and does not emphasize the students' passive acceptance of the English knowledge, but actively encourages students to carry out meaningful doubting and questioning, so that students can look for some good questions and determine the rationality hypothesis according to certain criteria. Therefore, in carrying out the specific teaching process, teachers should actively encourage students to give full play to their initiative, make them contact each other in the exploration of English learning materials as to each knowledge point, analyze and summarize knowledge, so as to steadily improve their ability of critical thinking.

\section{Constructing a New Student Evaluation System}

Teachers should reposition the evaluation system, not only focus on assessing students' knowledge acquisition ability, but also focus on their critical thinking ability, because developing good teaching evaluation methods can guide and motivate students' critical thinking. The traditional teaching evaluation methods and standards are single and rigid, limiting students' ideas and stifling students' imagination and creativity. To cultivate students' critical thinking ability, teaching evaluation can combine formative evaluation with summative evaluation. Formative evaluation is a comprehensive and more reasonable evaluation of the students' learning process. Teachers can evaluate students in open, relaxing and democratic atmosphere through questionnaires, interviews with students, classroom observation, students' self-assessment, mutual evaluation and parental evaluation. The evaluation includes not only the basic knowledge, but also the ability to acquire knowledge and apply knowledge, and communication skills, interpersonal skills and teamwork skills. The evaluation results can be described by descriptive language or grade scoring system, which can 
truly evaluate students' comprehensive quality, fully embody the students' personality and improve their critical thinking ability and innovative ability.

\section{E. Reasonable Design of Classroom Teaching}

In the course of English teaching, in order to effectively cultivate the students' critical thinking ability, it is necessary for the English class to be rationally designed. In the English reading class for example, first, before reading, teachers can assign students certain preview task, guide the students to make full use of the network and library resources to find relevant information, and ask the students to communicate with each other in the classroom, according to the title and illustrations of the text, as this process can be effective to exercise the critical thinking ability of students, improve the students' interest in the topic of the text, and prepare for reading. Secondly, in the process of reading, teachers can increase Chinese culture and integrate English learning into Chinese language and culture background, which can better promote the integration of two languages of English and Chinese and improve students' intercultural communicative competence. Textbook writers should examine the cognitive level of college students in different regions, and choose different Chinese cultural contents for different learning purposes and majors. Based on the cultural contrast between Chinese and English, teachers should organize English teaching activities, arrange teaching tasks to search cultural materials, and it can not only improve students' ability to identify culture, but also can cultivate students' initiative in autonomous learning.

\section{F. Improving Teachers' Critical Thinking Ability}

Teachers should realize the significance of critical thinking and equip themselves with critical thinking ability at first. In the new era, in addition to transmitting knowledge in textbooks, teachers should spend extra time in cultivating students' thinking ability in their classes, especially students' critical thinking ability. However, most of the EFL teachers fail to realize the importance of critical thinking ability in EFL teaching and learning in China. Most of them neglect the importance of cultivating students' critical thinking ability. Therefore, teachers should change their traditional notions toward critical thinking and realize the importance of critical thinking, and what's more, they should master professional knowledge of critical thinking. Only in this way can teachers permeate critical thinking into their teaching.

\section{G. Raise Students' Awareness of Critical Thinking Ability Training}

To cultivate students' critical thinking ability, the most important thing is that students should realize the importance of critical thinking ability and cultivate their own critical thinking ability consciously and initiatively. There are various methods that they can adopt to develop their own critical thinking ability. For example, they can organize or take part in such interesting and important activities as debating, oral presentation, and English writing competitions in class or in their spare time. Besides, they can raise their critical thinking ability by following such principles as, to keep an open mind, cultivate intellectual curiosity, challenge conventional wisdom, practice empathy, check the validity of your information, cultivate listening skills, heed their intuition, and withhold judgment until they are sure they have adequate information and so on. Moreover, students should also follow the three "Don'ts" principle: Don't take things at face value. Don't automatically accept authority. Don't tolerate ongoing and unproductive ambiguity. Students should make great efforts to jump out of thinking stereotype, challenge authority and convention, think bravely and independently, and try to develop their habit and ability of critical thinking.

\section{H. PBL Teaching Method}

Much different from the traditional teaching method, PBL teaching method considers students rather than teachers as the center of class. PBL teaching is often linked to some task or a bigger problem, involve learners into some question, and it can promote students to think. And in order to solve the problem, students need access to extracurricular information, induce, organize knowledge and skills learned which is beneficial to the cultivation of students' autonomous learning spirit. Furthermore, PBL teaching method is to isolate knowledge into the whole piece of stiff knowledge chain by analogy, and it highlights the teaching philosophy of "Classroom is the soul, and students and teachers are the key." In the teaching process of PBL, teachers gradually retreat, and they only coach, support and assist at the crucial moment, and the teacher is no longer the only knowledge base, but is a facilitator, a subject expert, information consultant for students' construction of knowledge. PBL teaching designs the real task, emphasizes the learning set to the complex and meaningful problem situation, and solves the problem by the learners' independent inquiry and cooperation, so as to learn the implicit knowledge from problem solving, and students can gradually form problem solving ability and independent learning skills, which can greatly improve the critical thinking ability of students.

\section{CONCLUSION}

The critical thinking ability of college students is an essential ability, and it is very important to develop students' critical thinking ability in college English teaching, but the cultivation of critical thinking is a long-term and arduous task, because the students generally accept traditional examination oriented education from kindergarten to university with a serious lack of critical thinking. Students generally love and are also accustomed to employ mechanical memory, 
and students' learning is passive, lack of independent learning ability, and they have the habit of waiting for the teacher to arrange the assignment, although they can do very well, but they are not used to exploring their own problems, lack of innovation spirit and ability. But this situation is difficult to change in a short period of time, and it needs the joint efforts of teachers, student, educators, parents and the whole society.

\section{ACKNOWLEDGEMENTS}

This study was financially supported by teaching reform project of Nanchang Normal University "The study of the influence of PBL teaching model on college students' critical thinking ability”(JGKT-15-18).

\section{REFERENCES}

[1] Burden, R. L. \& Williams, M. (2000). Psychology for language teachers: a social constructivist approach. Beijing: Foreign Language Teaching and Research Press.

[2] College English teaching guide committee English group. (2009). College English major syllabus. Beijing: Foreign language teaching and Research Press.

[3] Dewey, J. (1933). How we think: A restatement of the relation of reflective thinking to the education process. Boston: D.C. Heath \& Company.

[4] Elder, L., Paul, R. (1998). The role of Socratic questioning in thinking, teaching, and learning. Clearing House, 71(5):297-301.

[5] Facione, A P. (1990). Critical thinking: A statement of expert consensus for purposes of educational assessment and instruction: The Delphi Report Millbrae. California: The California Academic Press.

[6] Gui L., Zhang X. (2010). A quantitative and quantitative study of critical thinking in the graduation thesis of English major. Journal of Ningbo University, 32 (6): 103-106.

[7] Halpern, D.F. (1999). Teaching for critical thinking: Helping college students develop the skills and dispositions of a critical thinker. San Francisco: Jossey Bass.

[8] Han SJ. Yi Y. (2009). English writing teaching and cultivation of critical thinking ability. Foreign Language Literature, 1, 24-28.

[9] He S. L. (2015). Designing critical thinking questions to improve English classroom teaching efficiency. Teacher Training in Primary and Middle Schools, 10, 61-63.

[10] Hu S. F., Liu Z., Yang Z. Y. (2011). A survey and research on critical reading strategies of non English majors in general English course--Take cross-cultural communication course as an example. Heilongjiang Education (higher education research and evaluation), 1, 37-42.

[11] Huang Y. S. (1998). Absence of critical thinking. Foreign Language Teaching and Research, 7, 1-2.

[12] Li D. Q. (2017). Strategy for cultivating students' critical thinking ability in high school English reading teaching. Primary and Secondary School Foreign Language Teaching, 4, 15-21.

[13] Li L. W. (2011). Design of evaluation model for English major writing: Based on critical thinking ability training oriented writing. Foreign Language and Foreign Language Teaching, 1, 33-37.

[14] Li Z. H. (2014). A two-way connection between critical thinking ability training and college English teaching. Journal of Lanzhou University: Social Science Edition, 5, 136-140.

[15] Liu Q., Ma L. D. (2015). English writing and students' critical thinking ability training. Film Review, 4,107-108.

[16] Norris S. P. \& Ennis, R. H. (2001). Evaluating Critical Thinking. Pacific Grove, CA: Midwest Publications.

[17] Paul R.W. (1993) .Critical thinking: How to prepare students for a rapidly changing world. Santa Rosa, CA: Foundation for Critical Thinking.

[18] Paul R., Elder L. (2003). Critical thinking: Teaching students how to study. Journal of Developmental Education, 27(1):36-37.

[19] RickettsJ. C. et al. (2003). The effect of instructional delivery methods on the critical thinking disposition of distance learners and traditional on campus learners. Journal of Southern Agricultural Education Research, 1, 59-71.

[20] Siegel, H. (1988). Educating Reason: Rationality, Critical Thinking and Education. NY: Routledge.

[21] Sun Y. M., Yu H. Y. (2015). The cultivation of critical thinking ability in college English teaching from the perspective of the theory of output. Current Educational Scientific Research. 19, 62-64.

[22] Vaughn L. (2005). The power of critical thinking: effective reasoning about ordinary and extraordinary claims. New York: Oxford University Press.

[23] Wang Y. Z, Qu S.M. (2017). English classroom peer interaction activities design aiming at development of students' critical thinking ability. Teaching and Management: Theory edition, 8, 102-104.

[24] Wen Q. F., Wang J. Q., Zhao C. R., Liu Y. P., Wang H. M. (2009). Constructing the theoretical framework of Chinese foreign language college students' critical thinking ability measuring tool. Foreign Language Circles, 1, 37-43.

[25] Wen Q. F., Liu Y. P., Wang H. M. etc. (2010). The revision and reliability and validity test of measuring tools of Chinese foreign language college students' critical thinking ability. Foreign Language Circles, 4, 19-26.

[26] Zhong Q. Q. (2002). Prospect of critical thinking and teaching. Global Education, 1, 34-38.

Zhen Zhou was born in Ezhou, Hubei province, China in 1981. She received her master degree in English teaching method from Hubei University, China in 2008.

She is currently an associate professor in the School of Foreign Languages, Nanchang Normal University, Nanchang, China. Her research interests include English teaching psychology and English teaching method. 